
na publicidade: Femvertising e as "novas" representações do feminino. Consumer Behavior Review, 3(Special Edition), 24-37.

ISSN: 2526-7884

Editor: Prof. Dr. Marconi Freitas da Costa

Email da revista: cbr@ufpe.br
Avaliação: Double blind review

Recebido: 19 de agosto de 2019

Aceito: 21 de setembro de 2019

\title{
COMO SER MULHER NA PUBLICIDADE: FEMVERTISING E AS “NOVAS" REPRESENTAÇÕES DO FEMININO
}

\author{
Andrea Melo Bayone \\ Patricia Cecilia Burrowes
}

Andrea Melo Bayone é Bacharel em Comunicação Social/ Publicidade e Propaganda pela Escola de Comunicação da Universidade Federal do Rio de Janeiro ECO/UFRJ

E-mail: andrea92dc@hotmail.com

Patricia Celilia Burrowes é Professora Adjunta do Departamento de Expressão e Linguagens da Escola de Comunicação da Universidade Federal do Rio de Janeiro ECO/UFRJ.

E-mail: vermelha.red@gmail.com

Os autores agracedecem aos avaliadores pelos comentários para melhoria do artigo.

\begin{abstract}
Resumo
0 presente estudo tem como objetivo discutir se e como o uso do feminismo no marketing, no âmbito do femvertising, pode transmitir ideias de empoderamento feminino e promover uma representação da mulher na publicidade que fuja dos estereótipos. Para tal, são analisados três comerciais que contaram com a colaboração da consultoria de marketing feminista Think Eva: "\#EAíTáPronta?" e "Isso é Pra Mim" da marca Avon, e "Ser Mulher Faz Toda a Diferença" da Gillette Venus. A metodologia usada foi o estudo de caso, empregando, para análise individual dos comerciais, um modelo de leitura crítica da publicidade; e, para uma análise geral dos dados, as etapas de redução, exibição e conclusão/verificação. Os resultados indicam que os atributos do corpo feminino, as características comportamentais das mulheres e o incentivo ao empoderamento feminino são as questões mais revistas nos comerciais e diferem parcialmente das mensagens transmitidas na publicidade dita convencional.

Palavras-chave: Publicidade; Feminismo; Marketing Feminista; Femvertising.
\end{abstract}




\section{INTRODUÇÃO}

A relevância desse estudo deve-se à crescente discussão sobre o feminismo e a representação da mulher na sociedade contemporânea. Em 2017, o termo feminismo ocupou o topo das pesquisas e foi eleito a palavra do ano pelo dicionário norte americano Merriam-Webste $(G 1,2017)$. Anteriormente, em 2016 a Marcha das Vadias levou mulheres às ruas de 200 cidades em países como Índia, África do Sul, Alemanha e Brasil com ativistas de seios desnudos protestando contra o machismo e a culpabilização da mulher vítima de estupro (Cardoso \& Martino, 2016).

No mesmo ano, a intensa participação de mulheres no uso da hashtag "\#PrimeiroAssedio" em território nacional, iniciada por feministas, evidenciou a gravidade da problemática envolvendo o assédio sexual na sociedade e a importância da união entre mulheres no combate a essa questão (Visconti, 2015). Já em 2018, estudantes universitárias de todo o Chile se uniram para ocupar as faculdades protestando contra o machismo e a favor de uma educação não sexista (Agence France-Presse, 2018).

Dentro desse contexto, o feminismo vem sendo incorporado ao discurso da publicidade com a intenção de proporcionar um diálogo positivo entre as marcas e o público feminino. Para tal, uma das correntes usadas é o femvertising, termo que vem da combinação das palavras em inglês feminism e advertising. 0 termo ganhou notoriedade no evento chamado Advertising Week em Nova York, ao ser discutido pela diretora executiva da plataforma de mídia Sheknows, Samantha Skey.

Num painel mediado por Samantha no evento, houve discussões sobre os estereótipos negativos associados às mulheres na publicidade e como anúncios que investem no empoderamento feminino geram impacto positivo para elas (Nascimento \& Dantas, 2015). Segundo dados de pesquisa da plataforma SheKnows (2014):

91\% das mulheres acreditam que a maneira como são retratadas na publicidade impacta diretamente à sua autoestima; $51 \%$ das mulheres gostam de anúncios "pró- mulheres", pois acreditam que eles quebram barreiras de igualdade de gênero; $81 \%$ das entrevistadas afirmaram que os anúncios que retratam mulheres desta maneira são importantes para as novas gerações; $71 \%$ destas acreditam que as marcas devem ser responsáveis por usar publicidade para promover mensagens positivas para mulheres e meninas; $62 \%$ acham que qualquer marca pode entrar no espaço publicitário pró- feminino; 94\% acreditam que retratar as mulheres como símbolos sexuais em anúncios é prejudicial; mais da metade disseram ter comprado um produto porque gostaram de como a marca e sua publicidade retratam mulheres; e 46\% têm seguido uma marca nas mídias sociais, porque eles gostam do que a empresa representa. (SheKnows, 2014).

0 painel apontou ainda que as marcas estão buscando novas abordagens junto ao público feminino com a intenção de melhorar sua imagem e proporcionar uma maior identificação entre os produtos e serviços promovidos e o seu público- alvo.

\section{“NOVAS" FORMAS DE REPRESENTAR O FEMININO}

Apesar de parecerem, à primeira vista, estratégias recentes, a libertação da mulher e o feminismo vêm sendo utilizados com o objetivo de vender produtos e serviços há pelo menos 100 anos no cenário internacional (Duan, 2014). Um exemplo marcante foi o desfile de mulheres elegantes fumando na parada do dia da Páscoa em Nova York, no ano de 1929.

As mulheres foram contratadas por Edward Bernays, considerado "pai das relações públicas" e sobrinho de Sigmund Freud. Bernays foi chamado pela American Tobacco Company com a intenção de incentivar o público feminino a fumar em público depois da Primeira Guerra Mundial. As mulheres surgiram na parada fumando o que Bernays chamava de "tochas da liberdade", atitude que poderia ser considerada uma libertação e sinal de empoderamento feminino, já que nesse período, não era bem visto mulheres fumarem, pois era um comportamento reservado apenas aos homens (Duan, 2014). No anúncio é possível perceber a forte associação feita entre o ato de fumar e a autoconfiança da mulher. 


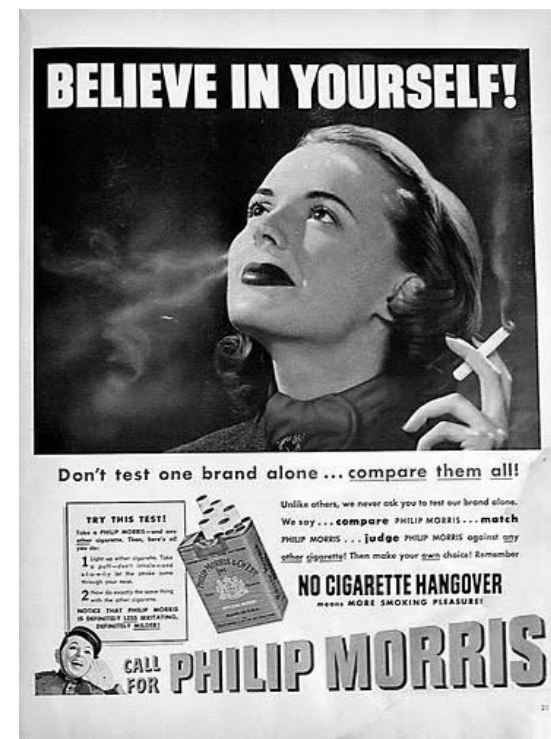

Fonte: Ellen (2014)

Figura 1: Anúncio de cigarro Philip Morris

Entretanto, foi a partir da década de 80 que a publicidade incorporou de forma mais acentuada as críticas do movimento feminista aos anúncios publicitários (Lana \& Souza, 2018). As mulheres passaram a ser mostradas em ambientes de trabalho, sendo retratadas com mais autonomia e com uma aparência maior de autoridade. Uma imagem que transmite autoestima, libertação e poder passou a ser ligada à mulher em alguns comerciais (Gill, 2007).

Os conceitos feministas se tornaram uma commodity da publicidade, o que pode ser entendido como um recurso para chamar a atenção do mercado e melhorar a imagem da marca, que busca estar alinhada com as aspirações do público consumidor (Lana \& Souza, 2018). Porém esse tipo de posicionamento foi adotado em graus variáveis por diferentes marcas, visto que até os dias atuais é possível observar empresas que utilizam propagandas consideradas machistas para vender produtos e serviços. Além disso, é comum a existência de críticas sobre o uso do feminismo no discurso publicitário, pois frequentemente ele é apresentado de forma domesticada, incentivando um empoderamento ligado a realizações limitadas ao alcance dos desejos individuais, afastando a ideia de luta coletiva presente no movimento (Lana \& Souza, 2018).

Uma ideia bastante empregada pelas marcas que apostam no uso do feminismo como estratégia de comunicação é o empoderamento feminino. 0 termo seria descrito como algo aliado à autonomia e participação, associada a um indivíduo ou grupo em estado de opressão, como ocorre com as mulheres atualmente (Horochovski, 2006). O empoderamento seria uma resposta contra a objetificação da mulher:

\begin{abstract}
Empoderamento é quase sinônimo de autonomia, na medida em que se refere à capacidade de os indivíduos e grupos poderem decidir sobre as questões que lhes dizem respeito, escolher, enfim entre cursos de ação alternativos em múltiplas esferas política, econômica, cultural, psicológica, entre outras. Desse modo, trata-se de um atributo, mas também de um processo pelo qual se aufere poder e liberdades negativas e positivas (Horochovski, 2006, p. 3).
\end{abstract}

De acordo com Nascimento e Dantas (2015) o empoderamento não é uma questão que possa ser solucionada de uma vez, sendo um estado de mudança contínua que evolui de acordo com o tempo presente. Apesar de o termo ser usado constantemente na contemporaneidade, não há concordância em relação aos seus conceitos e consequências.

Para Heck e Nunes (2016) a publicidade pode ter diferentes tipos de atuação de acordo com a forma como as peças publicitárias são criadas. As autoras (2016) acreditam que dependendo dos recursos escolhidos para a elaboração dos anúncios, uma publicidade pode se tornar "objetificadora" ou "empoderadora", visto que, enquanto prática discursiva, a publicidade é responsável pela difusão de modelos de comportamento através das representações, que podem ser vistas como positivas ou negativas pelo público.

Em relação ao femvertising, a disseminação de comerciais que empregam esse conceito conta com o crescente uso das mídias sociais e a sua possibilidade de "viralizar" conteúdos. A relevância do ambiente online é responsável por mudanças nas ações de marketing, que passam a ser medidas justamente pela sua capacidade de engajar os usuários, impulsionando as marcas no objetivo de impactar de forma positiva o público feminino, o mais ativo nas mídias sociais (Ciambriello, 2014). 
Em 2016, por exemplo, o público feminino representou $51,6 \%$ das vendas na internet no Brasil (Stocco, 2016). Além disso, de acordo com pesquisa realizada pela Confederação Nacional de Dirigentes de Lojistas e SPC Brasil (CDL, 2016), 64,8\% das mulheres admitiram que as redes sociais influenciam os seus hábitos de compra. Logo, o ambiente online representa um terreno fértil para a busca das marcas em disseminar ações publicitárias com o conceito de femvertising.

É fundamental que as marcas compreendam que incorporar o discurso do feminismo e empoderamento feminino em uma ou outra peça publicitária, ou até mesmo em todo o conceito de uma campanha, ainda não seria o suficiente. Segundo Nascimento e Dantas (2015), as marcas, ao adotarem esse tipo de posicionamento precisam também adotá-lo nas suas práticas, promovendo igualdade no ambiente de trabalho e nas ações que a empresa executa perante a sociedade. Contudo, um quesito fundamental seria como verificar a atuação das empresas, como a sociedade poderia garantir que a igualdade, o empoderamento e os ideais feministas estão de fato sendo levados a todas as esferas das corporações. Uma ação relevante, por exemplo, seria buscar uma maior representação de mulheres nos cargos de diretoras criativas das empresas. De acordo com o projeto The 3\% Movement, por exemplo, apenas 3\% desses cargos são ocupados por mulheres nos EUA (Merigo, 2016).

\section{CONSULTORIA DE MARKETING THINK EVA}

Para analisar o uso do feminismo na publicidade dentro do âmbito do femvertising, o presente estudo examinou três comerciais que receberam suporte da consultoria de marketing feminista Think Eva: “\#EAíTáPronta?” e "Isso é Pra Mim" da marca Avon, e "Ser Mulher Faz Toda a Diferença" da Gillette Venus. A consultoria foi criada em fevereiro de 2015, sendo descrita como um "núcleo de inteligência do feminino" (Think Eva, 2018).

Nascida da iniciativa das jornalistas Juliana de Faria, Maíra Liguori e da publicitária Nana Lima, a consultoria tem o objetivo de auxiliar marcas, ONGs, agências e instituições que desejam uma forma de abordagem ao público feminino que não perpetue os estereótipos negativos utilizados na publicidade tradicional.

A atuação da Think Eva é descrita pelas fundadoras como "de dentro para fora", pois a intenção seria modificar o cenário dentro das empresas e que isso refletisse na comunicação com as consumidoras. Para tal, elas afirmam que não basta passar um "pincel feminista" ou colocar palavras de empoderamento nas campanhas, mas asseveram que é preciso um trabalho maior de conscientização das empresas sobre a importância de um diálogo respeitoso com o público feminino (Mena, 2015).

A Think Eva atua em duas frentes principais. A primeira é a estratégia, que compreende desde o planejamento até a criação de campanhas que reflitam os ideais do feminismo. A segunda frente é a educação, que abarca palestras, debates e workshops realizados nas empresas clientes da consultoria. 0 objetivo é oferecer conteúdos que auxiliem a discutir questões fundamentais na vida das mulheres e solucionar dúvidas dos profissionais em relação a como se conectar com as necessidades da mulher atual (Think Eva, 2018).

A consultoria tem ainda uma estreita relação com a ONG feminista Think Olga. A ONG, criada em 2013 pela jornalista Juliana de Faria, segundo a descrição de seu site tem como objetivo "empoderar as mulheres através da informação. 0 projeto é um hub de conteúdo que aborda temas importantes para o público feminino de forma acessível" (Think Olga, 2018).

Atualmente o Think Olga conta com diferentes frentes de atuação como projetos especiais, artigos, manuais de jornalismo humanizado e agenda de eventos, que são divulgadas no site e outras redes sociais da ONG. Sua idealizadora foi eleita pela revista Cosmopolitan US e pela Clinton Foundation uma das oito mulheres inspiradoras do mundo. Além disso, recebeu o Troféu Mulher Imprensa 2015 na categoria Redes Sociais e foi finalista do prêmio Cláudia na categoria Trabalho Social, pela sua atuação na ONG (Mena, 2015).

A grande aproximação entre a Think Eva e a Think Olga serviu como incentivo para que os comerciais que contaram com a atuação dessa consultoria fossem analisados para este estudo, visto que a Think Eva dispõe de um contato ativo com as questões do movimento feminista, 
já que conta com uma mesma colaboradora da Think Olga.

\section{MARKETING DE IDENTIDADE E A REPRESENTAÇÃO DAS MINORIAS}

0 atual posicionamento das marcas mostra uma preocupação cada vez maior em acompanhar os movimentos sociais que influenciam os indivíduos, produzindo ações de marketing cada vez mais eficazes e que de certa forma interagem com as preocupações do seu público consumidor. Tal questão pode ser relacionada à noção de marketing de identidade descrito por Naomi Klein Em seu livro "Sem Logo: A Tirania das Marcas em um Planeta Vendido". A autora (2004) relata o aparecimento do marketing de identidade no início dos anos 90.

Segundo Klein (2004), nesse período houve uma grande efervescência nas universidades em relação à discussão da representação das minorias, seja nas bibliografias acadêmicas, na mídia e etc. A questão da representação virou a chave para resolver os problemas das minorias e não só mais um dos instrumentos que poderiam ser utilizados, por causa da ausência de metas políticas tangíveis relacionadas a essa temática. A mídia e o currículo educacional passaram a ser vistos como a origem principal dos problemas referentes às minorias, tanto pela criação de estereótipos negativos quanto pela falta de representação (Klein, 2004).

A autora (2004) explica que a sua geração cresceu com a mídia, envolta na cultura pop e por isso acreditava que através dela poderia mudar o mundo. Esse posicionamento não passou despercebido pela área de marketing das empresas e o discurso de representação das minorias passou a ser absorvido pela mídia e a cultura pop em geral. Klein (2004, p. 177) afirma que "nossa insistência nas supremas identidades sexuais e raciais contribuíram para grandes estratégias de conteúdo de marca e marketing segmentado". Logo, as marcas passaram a fazer uso dos discursos das minorias como forma de atingir os nichos dos seus mercados consumidores.

Como apontado pela autora (2004), o problema seria o fato da mudança de posicionamento das empresas não ter origem numa transformação política, mas ser apenas resultado da observação de dados econômicos.
Klein (2004) cita o livro "Rocking the Ages" de Yankelovich Partners, em que importantes pesquisadores do consumo americano afirmam que a palavra "diversidade" define a geração X, visto que esses indivíduos estariam mais propensos à pluralidade cultural, política, social, sexual e racial. Por isso, as marcas logo perceberam que era necessário criar "identidades de marca" com o objetivo de manter sua competitividade no mercado. Um exemplo nesse sentido veio da encenação de um protesto feminista no Boulevard Chanel, avenida francesa criada dentro do Grand Palais em Paris, após um desfile do estilista Lagerfeld da marca Chanel em 2014. No evento, modelos como Cara Delevingne, Kendall Jenner e Gisele Bundchen desfilaram com cartazes contendo dizeres como "mulheres primeiro", "eles por elas" e outros (Chernikoff, 2014).

Para Klein (2004) essas representações das minorias na publicidade podem sim ser consideradas positivas para os movimentos sociais em alguns aspectos, contudo é inegável que as marcas ganham milhões à custa de determinados posicionamentos. A autora (2004) sinaliza que algo claro dentro dos movimentos militantes na atualidade é o fato das políticas de diversidade nas representações das minorias não estarem surtindo impacto significativo no combate ao sistema de opressão.

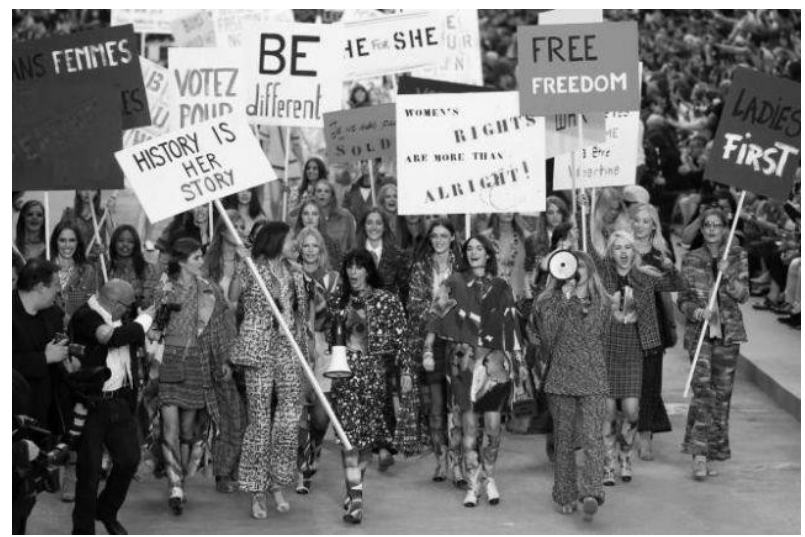

Fonte: Ellen (2014).

Figura 2: Imagem da encenação de protesto da grife Chanel no Boulevard Chanel

Na verdade, toda a questão da representação culminaria no consumo de produtos e serviços, como apontou a cantora Ann Powers em relação ao movimento girl power na mídia: 
$\mathrm{Na}$ interseção entre o feminino convencional e a Garota em evolução, o que está surgindo não é uma revolução, mas um shopping (...) Assim, um movimento genuíno evolui para uma enorme farra de compras, onde as garotas são encorajadas a pegar nas prateleiras qualquer identidade que seja mais adequada para elas (Powers como citado em Klein, 2004, p. 181).

Apesar das reflexões da autora (2004) sobre a utilização da representação das minorias no marketing de identidade ser ambientadas no contexto dos EUA, a forte globalização e a presença de marcas internacionais propiciam um ambiente semelhante no Brasil, com marcas se apropriando cada vez mais de determinados discursos das minorias como forma de posicionamento.

\section{METODOLOGIA DE PESQUISA}

$O$ estudo seguiu como metodologia de pesquisa o estudo de caso com abordagem da análise do discurso. Dentro dessa perspectiva, foi utilizado o modelo de leitura crítica descrito por Malmelin (2010 como citado em Machado, Burrowes \& Rett, 2017) para análise individual dos comerciais. A proposta desse modelo é o desenvolvimento de uma literacia publicitária composta por quatro dimensões: informacional, estética/visual, retórica e promocional.

A literacia informacional distinguiria as fontes de informação e entenderia suas intenções com o propósito de julgar a sua confiabilidade. A literacia estética/visual visa o entendimento dos aspectos artísticos e de entretenimento da publicidade, para que seja possível identificar e interpretar os sentidos implícitos, dificilmente percebidos através da linguagem verbal.

Já a literacia retórica tenciona observar as estratégias de persuasão da publicidade no texto verbal, com a finalidade de compreender as técnicas de marketing, público alvo, tipo de tom de voz, entre outros. Por fim, a literacia promocional constata os objetivos comerciais da mídia de forma geral e como eles podem surgir de diferentes formas, como marketing de conteúdo, patrocínios, parcerias e etc (Malmelin, 2010 como citado em Machado, Burrowes \& Rett, 2017). Visto que a observação da dimensão promocional torna-se complexa para esse tipo de análise, pois seria necessário ter acesso ao planejamento de mídia e outros dados de difícil acesso, ela não será usada para o estudo do corpus dessa pesquisa.

Além disso, uma análise mais geral das peças publicitárias empregou três etapas descritas por Miles e Hubermam (1994 como citado em Gil, 2008), sendo elas redução, exibição e conclusão/verificação. Na redução dos dados, há uma um processo de triagem e simplificação das informações obtidas.

A exibição organiza os dados escolhidos de forma que seja possível identificar diferenças e afinidades entre essas informações, através da elaboração de diagramas, mapas, textos e outros. Já na conclusão/ verificação é necessária uma inspeção do significado dos dados, seus parâmetros e justificativas. Nas considerações finais, esse modelo apresentará uma visão geral dos principais tópicos verificados nos anúncios.

Para isto, foram criadas três categorias de análise: 1) Características do corpo feminino Atributos físicos das mulheres exibidas nos anúncios; 2) Características comportamentais das mulheres - o perfil comportamental mostrado nos anúncios; 3) Ideais de empoderamento da campanha - promoção do empoderamento feminino. Os dados reunidos sobre a Think Eva e os comerciais foram publicados no final de 2016 e ao longo de 2017, sendo coletados e examinados no período de abril a maio de 2018 .

\section{ANÁLISE DOS COMERCIAIS DA GILLETTE VENUS}

0 primeiro comercial a ser examinado, "\#Eaítápronta?", mostra o novo posicionamento da Color Trend, uma linha de cosméticos da Avon direcionada ao público jovem. A campanha, estrelada por Pablo Vittar, Iza e Mariana Mello, apresenta mulheres com diferentes características físicas e comportamentais, com foco principal em mostrar o empoderamento feminino através da união.

Isto é exibido através de referências, algumas vezes implícitas, que relembram momentos históricos ou situações cotidianas vividas pelas mulheres. Elas utilizam a maquiagem como elemento de conexão e todas se arrumam para um grande evento de mulheres, ápice do comercial. 0 enredo faz uma 
contraposição entre uma determinada situação esperada pelo público e outra idealizada pelo comercial. Mariana, por exemplo, anda pela rua e, ao perceber que é seguida por um carro, apresenta um semblante tenso. Ela se aproxima do veículo e quando o vidro da janela se abre algumas mulheres negras sorriem e Mariana entra confiante no automóvel.

Há a intenção de refletir sobre uma situação cotidiana de vulnerabilidade feminina, pois é comum mulheres se sentirem inseguras quando um carro desconhecido se aproxima. No anúncio é produzida uma realidade em que mulheres têm a liberdade de ir e vir, além de cuidarem umas das outras ao oferecem carona, por exemplo. A partir dessa cena são apresentadas outras que fazem o mesmo contraste entre um desfecho negativo já esperado pelo público para determinadas situações e o que aconteceria numa realidade utópica, idealizada no comercial.

Seguindo o modelo proposto por Malmelin (2010 como citado em Machado, Burrowes \& Rett, 2017), podemos apontar alguns elementos importantes que fazem parte da dimensão estética/visual do anúncio. Nas cenas em geral há contraste entre ambientes internos escuros e outros externos com abundante presença de luz.

$\mathrm{Na}$ cena final da reunião entre as mulheres de forma festiva, esse contraste apresenta um contraponto entre a permanência da força feminina no ambiente privado e a exposição da união de mulheres num ambiente externo, colorido, simbolizando o movimento de tornar pública a luta e a relevância do feminismo. Ligado à dimensão retórica, podemos ver uma frase escrita no início do anúncio "Color Trend tá de cara nova" e "Mas um mundo novo não depende só da gente".

A marca coloca a sua voz ao lado das mulheres, usando como forma de persuasão o seu suposto protagonismo junto ao público feminino na conquista dessa realidade mais justa pautada por ideias feministas e de empoderamento. Como visto na fundamentação teórica é usual marcas "pegarem carona" nos movimentos sociais para se alinharem as transformações da sociedade e aos desejos do público, muitas vezes apenas visando manter os lucros (Klein, 2004).

Outra questão ligada a dimensão retórica é a música "Não Deixe o Samba Morrer" que permeia todo o comercial, sendo uma forma de trazer um apelo emocional para a temática da união feminina. Foi elaborada uma história, um significado, um sentimento a ser atribuído a um produto impessoal, recurso usado com frequência pela publicidade (Rocha, 2001).

A intenção é que o discurso de empoderamento e união feminina funcione como uma estratégia de branding da empresa ao associar a Color Trend ao feminismo. 0 indivíduo ao adquirir o produto, não estaria comprando apenas um batom ou um rímel, mas sim um ideal. A mensagem torna-se atraente aos indivíduos ao serem usadas frases fáceis de memorizar, conteúdos que dialoguem com a vivência do público (Carvalho, 2000).

Outra estratégia de persuasão relacionada aos jovens é o uso de palavras conhecidas do vocabulário desse público, que surgem escritas em algumas cenas nas frases "Não deixe o rolê acabar", "Não deixe a vibe acabar", "Não deixe o bonde acabar", entre outras. Já frases como "Não deixe o amor acabar" e "Não deixe a empatia acabar" fornecem um apelo emocional, comum nas estratégias publicitárias. A dimensão informacional é pouco enfatizada no anúncio, os produtos servem como elo entre as mulheres e são bastante usados durante o comercial.

Seguindo o modelo proposto por Malmelin (2010 como citado em Machado, Burrowes \& Rett, 2017), podemos apontar alguns elementos importantes que fazem parte da dimensão estética/visual do anúncio. Nas cenas em geral há contraste entre ambientes internos escuros e outros externos com abundante presença de luz.

$\mathrm{Na}$ cena final da reunião entre as mulheres de forma festiva, esse contraste apresenta um contraponto entre a permanência da força feminina no ambiente privado e a exposição da união de mulheres num ambiente externo, colorido, simbolizando o movimento de tornar pública a luta e a relevância do feminismo. Ligado à dimensão retórica, podemos ver uma frase escrita no início do anúncio "Color Trend tá de cara nova" e "Mas um mundo novo não depende só da gente".

A marca coloca a sua voz ao lado das mulheres, usando como forma de persuasão o seu suposto protagonismo junto ao público feminino na conquista dessa realidade mais justa pautada por ideias feministas e de empoderamento. Como visto na fundamentação teórica é usual marcas "pegarem carona" nos 
movimentos sociais para se alinharem as transformações da sociedade e aos desejos do público, muitas vezes apenas visando manter os lucros (Klein, 2004).

Outra questão ligada a dimensão retórica é a música "Não Deixe o Samba Morrer" que permeia todo o comercial, sendo uma forma de trazer um apelo emocional para a temática da união feminina. Foi elaborada uma história, um significado, um sentimento a ser atribuído a um produto impessoal, recurso usado com frequência pela publicidade (Rocha, 2001).

A intenção é que o discurso de empoderamento e união feminina funcione como uma estratégia de branding da empresa ao associar a Color Trend ao feminismo. 0 indivíduo ao adquirir o produto, não estaria comprando apenas um batom ou um rímel, mas sim um ideal.

A mensagem torna-se atraente aos indivíduos ao serem usadas frases fáceis de memorizar, conteúdos que dialoguem com a vivência do público (Carvalho, 2000). Outra estratégia de persuasão relacionada aos jovens é o uso de palavras conhecidas do vocabulário desse público, que surgem escritas em algumas cenas nas frases "Não deixe o rolê acabar", "Não deixe a vibe acabar", "Não deixe o bonde acabar", entre outras. Já frases como "Não deixe o amor acabar" e "Não deixe a empatia acabar" fornecem um apelo emocional, comum nas estratégias publicitárias. Contudo não há especificações sobre as características tangíveis dos cosméticos como cores, modelos e etc. Apesar da diversidade de corpos apresentados, o quesito beleza ainda é visto como fundamental, visto que as mulheres ainda mostram intensa preocupação com a questão estética, já que trata-se de um comercial de cosméticos.

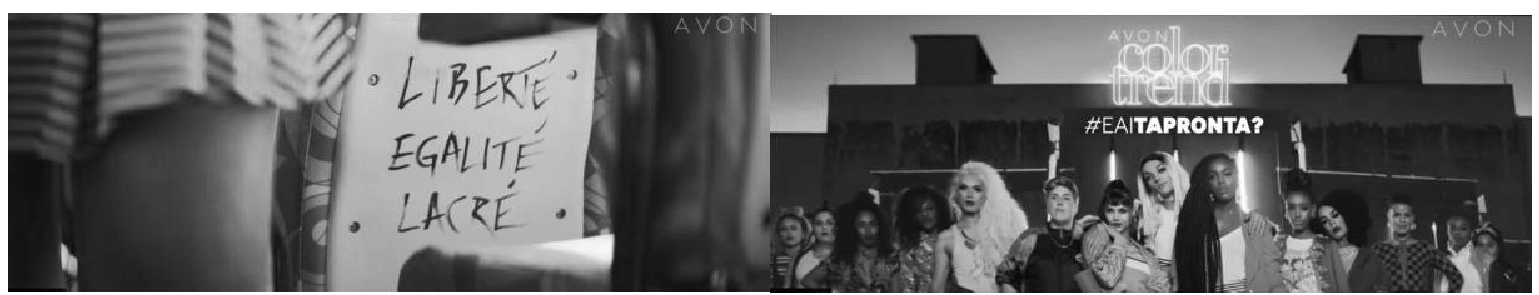

Fonte: YouTube (2017)

Figuras 3 e 4: Cenas do comercial "\#EAíTáPronta?" da marca Avon

O segundo comercial, "Isso é pra mim" da linha de lingerie Avon Signature, traz uma canção produzida por Gaby Amarantos, Pitty e Daniela Mercury. 0 anúncio representa o conceito "(Re)conheça a sua Lingerie" que estampou o catálogo Avon Moda \& Casa em 2017. Mulheres com diferentes características físicas dançam num cenário branco com molduras e demonstram união através de gestos, posturas e comportamentos.

Em determinado momento, a imagem escurece e algumas mulheres quebram as molduras brancas de maneira agressiva, sinalizando poder sobre o corpo e aparência. É possível entender a cena como a representação de quebra de estereótipos de beleza feminina e o empoderamento da mulher em relação as suas escolhas. A composição também faz referência ao empoderamento feminino ao trazer frases como "visto meu corpo para mim mesma","visto minha própria beleza, me visto de amor", "tomar posse desse corpo, acolhendo quem eu sou". Não há sexualização dos corpos apesar do uso das roupas íntimas e as características tangíveis das mesmas como cores e modelos também não são abordadas, questão deixada para os folhetos direcionados para as vendas.

A dimensão estética/visual é composta pelo cenário branco e o direcionamento frontal da câmera na maioria das cenas dá ênfase aos corpos e roupas das mulheres. Um lettering surge na tela realçando algumas partes da mensagem verbal presente na música como "me visto de amor" e "eu sou assim", relacionada à dimensão retórica.

As coreografias são vigorosas e expressam liberdade e domínio do próprio corpo. É usada a hashtag "\#issoépramim" que pretende 
contestar a usual afirmação "É lindo, mas não é pra mim" feita por mulheres ao verem um vestuário num manequim ou modelo com formas corporais muito distintas das delas. A ideia é transmitir a mensagem de que as lingeries da Avon Signature são para todas as mulheres, reforçando o conceito da campanha "(Re)conheça a sua lingerie".

Durante toda a canção há uma forte idealização das lingeries e consequentemente da moda, como sendo algo além da representação do indivíduo, mas sim o próprio indivíduo em si. Frases como "visto meu corpo com o que sou", "o que visto é o que sou" validam essa ideia, colocando a vestimenta e a aparência física como fatores primordiais na vida da mulher. Sentenças como "celebrando a beleza diversa de formas e cores" e "ocupo minha própria beleza, me visto de amor" buscam influenciar os sentimentos e percepções do público. 0 uso das palavras é intencionalmente feito para preencher o vazio interior dos indivíduos com ideias de amor, autoaceitação e contentamento em relação ao próprio corpo (Carvalho, 2000).

A dimensão informacional dos produtos é bem sutil. Apesar de todas as personagens vestirem lingeries da linha Avon Signature, não há uma menção clara aos tamanhos disponíveis, cores ou outros atributos das peças. Isto se relaciona com o uso do valor social do produto descrito por Schroder e Vestergaard (2000), em que são desprezadas as características e benefícios em prol da associação do produto com um ideal. É possível entender que a intenção do anúncio é transmitir a mensagem de autoaceitação corporal e relacioná-lo com a marca.

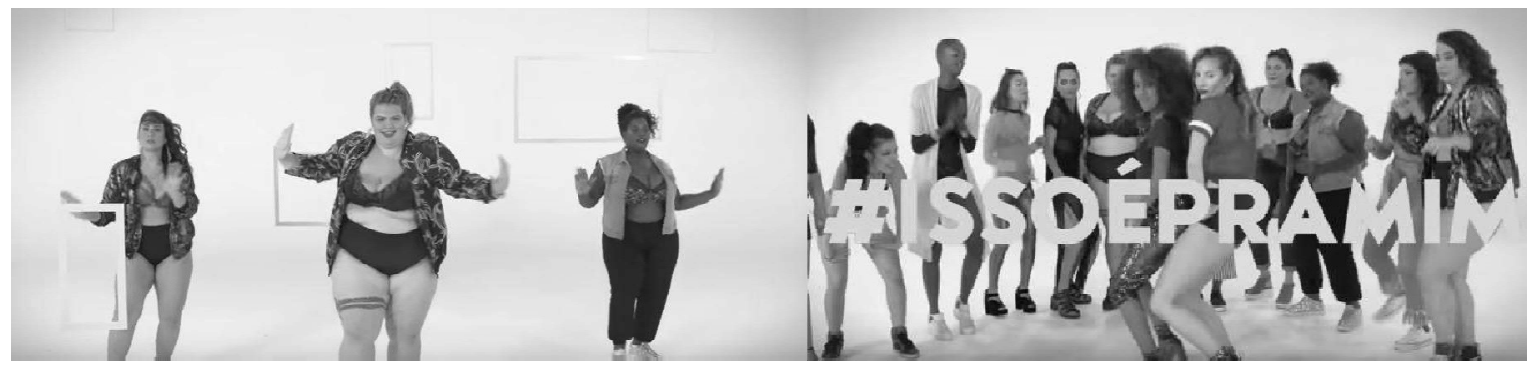

Fonte: YouTube (2017)

Figuras 5 e 6: Cenas do comercial "Isso é Pra Mim" da marca Avon Signature

Já o anúncio "Ser Mulher Faz Toda a Diferença" foi a primeira incursão da Gillette Venus no campo do femvertising. No comercial, cenas de mulheres com diferentes características físicas enfrentando dificuldades na vida cotidiana são exibidas, enquanto uma voz em off discorre sobre o fato do mundo não ter sido feito para as mulheres, mas sim para os homens. Uma jovem ruiva anda de scarpin azul num grande centro urbano e tropeça na calçada.

Em seguida outra mulher, de pele morena com cabelos lisos e escuros tenta sem sucesso alcançar uma roupa na última prateleira de um armário, mostrando uma expressão de cansaço no rosto. A situação se inverte quando uma das protagonistas do comercial, Sabrina Sato, pega a lâmina de depilação da Gillette Venus, sugerindo que a marca entende o universo das mulheres. Dessa cena em diante as mulheres "vencem" as dificuldades colocando uma caixa abaixo dos pés para alcançar lugares altos, por exemplo, mostrando através dos seus semblantes força e determinação.

A maneira de enfrentar tais situações assemelha-se a uma adaptação das mulheres a um mundo que continuará não sendo feito para elas. Em oposição aos comerciais da Avon analisados anteriormente, o empoderamento feminino é mostrado de forma individualizada, não havendo um aspecto de união por parte das mulheres. Tal fato associa-se de certa forma a uma crítica ao uso de um "feminismo dócil" na publicidade, tocante a um empoderamento ligado a conquista de desejos individuais, afastado do caráter de luta coletiva representada pelo movimento feminista (Lana \& Souza, 2018).

Nos moldes do modelo proposto por Malmelin (2010 como citado em Machado, Burrowes \& Rett, 2017), de acordo com a 
interpretação da dimensão estética/visual, percebemos no comercial mulheres apresentando diferentes formas físicas com cabelos lisos, cacheados e crespos, com a pele branca, negra, marcada por tatuagens, gordas e magras. Essa diversidade representa estereótipos de mulheres jovens, "descoladas" e independentes, o que pode ser inferido pelas vestimentas usadas, tatuagens, cabelos coloridos e os ambientes onde são retratadas como local de trabalho, dirigindo carro e etc. Duas mulheres famosas na mídia estão em destaque no anúncio, Sabrina Sato e Karol Conka.

Com relação à dimensão retórica, como dito anteriormente, a mensagem transmitida pela voz em off afirma que o mundo não foi feito para as mulheres e as imagens concentram-se em mostrar situações de dificuldades da rotina. 0 contexto muda apenas quando o produto é apresentado, visto que nesse momento o texto diz "E quando isso acontece, a gente sente. Sente na pele, nas formas, no toque" referindo-se à lâmina, com o intuito de mostrar como a marca entende o corpo da mulher. Porém, não há nenhuma explicação tangível que comprove o motivo do produto ser mais adequado ao corpo da mulher. A cor rosa surgiria como única característica explícita que diferencia a lâmina de sua versão direcionada ao público masculino.

$\mathrm{Na}$ cena final, as mulheres participantes da produção do comercial são mostradas. Os nomes de todas as integrantes da equipe são exibidos na tela com o objetivo de mostrar que todas eram mulheres, contudo não há menção a equipe de criação do roteiro. Tal fato não permite ao público averiguar se as ideias e princípios transmitidos pela área de criação também foram criados por mulheres.

A dimensão informacional pode ser vista apenas com a exibição do produto em algumas cenas do anúncio. Não há nenhuma apresentação das características tangíveis da lâmina e nem demonstração da sua utilização. 0 comercial prefere apostar na subjetividade ligada a um suposto discurso de empoderamento feminino como forma de posicionar a marca dentro da realidade contemporânea e da proposta do marketing feminista.

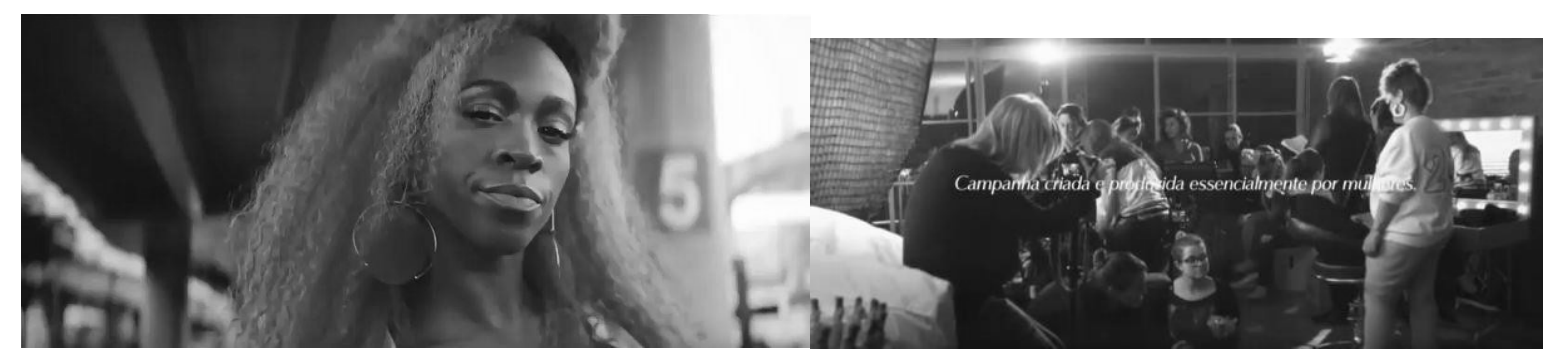

Fonte: YouTube (2016)

Figuras 7 e 8: Cenas do comercial "Ser Mulher Faz Toda a Diferença" da marca Gillette Venus

As três propagandas analisadas buscaram caminhos que diferem em partes da representação da mulher na publicidade tradicional, com o objetivo de atingir um maior grau de satisfação do público feminino. No material investigado, em relação aos estereótipos ligados ao tipo físico, os três comerciais procuram utilizar atrizes com diferentes características corporais para representar a diversidade de mulheres do território brasileiro. Tipos de cabelos distintos, muita ou pouca gordura corporal e peles de diferentes cores foram mostrados, diferenciando-se em partes das características físicas principais presentes no discurso publicitário: beleza, magreza e juventude (Santos, 2016).

Em relação ao quesito beleza, percebe-se uma distinção do discurso tradicional apenas em relação ao padrão europeu normalmente utilizado, em que vigoram o cabelo liso e pele clara. Todavia, as mulheres dos comerciais continuam maquiadas, com a pele bem cuidada, unhas feitas e bem vestidas, características que podem também ser associadas à boa aparência.

Já a magreza foi uma característica bastante questionada nos anúncios, visto que todos os comerciais continham mulheres gordas, apesar do anúncio da Gillette Venus dar pouco destaque à questão. 0 quesito juventude não foi 
muito modificado e prevaleceu em todos os comerciais, não havendo ênfase em personagens idosas. Este fato pode ser explicado pelo direcionamento dos anúncios ao público jovem. Contudo, sendo o feminismo um conjunto de movimentos políticos, econômicos e sociais que visa a conquista de direitos igualitários para as mulheres, é questionável a segmentação do movimento da forma que convém às marcas em prol de práticas mercadológicas. A presença de mulheres com alguma deficiência física também não foi verificada.

Sobre as características psicológicas das mulheres, é percebido nos comerciais “\#EAíTáPronta?" da Avon e "Ser Mulher Faz Toda a Diferença" da Gillette Venus a ideia de que há um dever da mulher em cuidar da beleza e sua própria aparência, que vigora no discurso publicitário tradicional (Cruz, 2016). De forma implícita, o amplo uso de batom, rímel ou a alusão à depilação feminina reforçam a manutenção da preocupação que as mulheres desenvolveram socialmente em relação à aparência.

Sendo marcas voltadas para cosméticos e cuidados com o corpo, é uma tarefa labiríntica produzir um comercial que não privilegie preocupações estéticas e ao mesmo tempo venda esse tipo de produto. É possível mencionar uma relação com o anúncio "Retratos da Real Beleza" da marca Dove, considerado pioneiro ao promover uma percepção de beleza mais ampla e inclusiva, sendo protagonizado por mulheres "reais" com diferentes idades, tipos físicos e raças.

A estratégia do anúncio, utilizada a mais de 10 anos pela marca, aumentou as vendas desde o início da campanha até 2015 de US\$2,5 bilhões para US\$ 4 bilhões (Fabris, 2015).
Entretanto, para Lysardo e Dias (2007) não houve nenhuma ruptura com o culto a aparência e a beleza no posicionamento da Dove, já que as mulheres são incitadas a comprar produtos visando valorizar a sua "beleza natural".

Nos comerciais analisados nesse estudo, os comportamentos perceptíveis de forma geral são as atitudes de independência, força $\mathrm{e}$ liberdade das mulheres, demonstradas através de expressões faciais, posturas e formas de se portar. Os três comerciais investem nessa representação da mulher independente e responsável por si. A presença de homens cisgênero é percebida nos anúncios “\#EAíTáPronta?" e "Ser Mulher Faz Toda a Diferença", contudo eles não exercem nenhum protagonismo.

O empoderamento é trabalhado com focos diferentes nos três comerciais. No "\#EAíTá Pronta?" a questão é exposta sob o ponto de vista da união feminina, já que a ideia principal seria a atuação das mulheres em conjunto com a finalidade de combater preconceitos e promover a igualdade. 0 anúncio "Isso é Pra Mim" enfatiza a autoaceitação e a livre escolha sobre o seu próprio corpo e a maneira de se vestir, além de também destacar a harmonia entre as mulheres e o apoio mútuo. Já no comercial "Ser Mulher Faz Toda a Diferença" o empoderamento é visto pelo viés da autonomia feminina, exibindo mulheres que tomam decisões e enfrentam as dificuldades do cotidiano de forma independente, sem o auxílio de outros indivíduos.

Como forma de sintetizar as informações apresentadas, as campanhas descritas serão categorizadas a seguir de acordo com as definições estabelecidas anteriormente:

\begin{tabular}{|l|l|l|l|}
\hline \multicolumn{1}{|c|}{ Campanha } & \multicolumn{1}{|c|}{$\begin{array}{c}\text { Características do } \\
\text { corpo feminino }\end{array}$} & $\begin{array}{c}\text { Características } \\
\text { comportamentais das } \\
\text { mulheres }\end{array}$ & $\begin{array}{c}\text { Ideias de } \\
\text { empoderamento } \\
\text { dentro da temática da } \\
\text { campanha }\end{array}$ \\
\hline Avon: E aí, Tá Pronta? & $\begin{array}{l}\text { Mulheres brancas, } \\
\text { pardas negras, magras, } \\
\text { gordas. } \\
\text { Cabelos crespos, } \\
\text { cacheados, lisos e } \\
\text { travestis. }\end{array}$ & $\begin{array}{l}\text { União com outras } \\
\text { mulheres promovendo } \\
\text { a força feminina na } \\
\text { sociedade, consciência } \\
\text { sobre o direito ao } \\
\text { respeito, preocupações } \\
\text { estéticas. }\end{array}$ & $\begin{array}{l}\text { Quando a gente se une o } \\
\text { mundo se transforma. }\end{array}$ \\
\hline Avon: Isso é Pra Mim & Mulheres brancas, & União promovendo o & Isso é pra mim, eu sou \\
\hline
\end{tabular}




\begin{tabular}{|l|l|l|l|}
\hline & $\begin{array}{l}\text { pardas, negras, magras, } \\
\text { gordas. Cabelos crespos, } \\
\text { cacheados, lisos, carecas } \\
\text { e travesti. }\end{array}$ & $\begin{array}{l}\text { empoderamento, amor } \\
\text { próprio e autoaceitação } \\
\text { corporal. }\end{array}$ & assim \\
\hline $\begin{array}{l}\text { Gillette Venus: Ser } \\
\text { Mulher Faz Toda a } \\
\text { Diferença }\end{array}$ & $\begin{array}{l}\text { Mulheres brancas, } \\
\text { pardas, negras, } \\
\text { asiáticas, magras, } \\
\text { curvilíneas. Cabelos } \\
\text { cacheados, lisos. }\end{array}$ & $\begin{array}{l}\text { Força para superar } \\
\text { dificuldades, resiliência, } \\
\text { preocupações estéticas. }\end{array}$ & $\begin{array}{l}\text { Ser mulher é mais do } \\
\text { que ser diferente, é } \\
\text { fazer a diferença. }\end{array}$ \\
\hline
\end{tabular}

Fonte: Elaborado pelas autoras (2018)

Quadro 1: Características de representação da mulher nos comerciais

Um ponto a ser mencionado é a necessidade das marcas agirem além da produção de campanhas pontuais na promoção do discurso do femvertising, desempenhando um maior compromisso com o ambiente empresarial e a sociedade como um todo. A Think Eva expõe no seu site que há uma preocupação da consultoria nesse sentido, afirmando que as empresas precisam assumir um "compromisso inegociável" com o ativismo em prol da causa feminista e não agir apenas movidas por modismos (Think Eva, 2017). Entretanto, não há descrita no site da empresa nenhuma forma de verificação por parte da Think Eva sobre as ações das marcas que ela atende, com o objetivo de apurar se as empresas estão realmente engajadas com essa causa. Sendo a consultoria uma empresa relativamente nova, com pouco mais de três anos de atuação, ainda é cedo para afirmar que o trabalho de uma consultoria com essa abordagem específica será adotado de forma prolongada pelas marcas.

\section{CONSIDERAÇÕES FINAIS}

No presente estudo, foi percebido que as campanhas que contaram com a colaboração da consultoria de marketing feminista Think Eva focam a sua mensagem na difusão de ideias como união entre as mulheres, autoaceitação corporal e atitudes de independência em relação a outros indivíduos, em detrimento de apresentar as características tangíveis dos produtos. Como citado anteriormente, a preocupação maior das marcas que utilizam o femvertising é introduzir o empoderamento feminino no seu discurso de comunicação. A intenção é dialogar de forma mais abrangente com o seu público consumidor e formar uma imagem positiva.
A representação tradicional da imagem da mulher na publicidade vem sofrendo duras críticas por parte das consumidoras, que geram impacto através da utilização dos meios online e redes sociais para difundir críticas e opiniões negativas. Nesse sentido, as campanhas pesquisadas fazem da internet um forte meio de divulgação dos comerciais, através da criação de canais no YouTube e uso de hashtags nas mensagens dos anúncios, com o intuito de "viralizar" conteúdos, melhorando sua aceitação por parte do público.

Um dos principais pontos trabalhados nesses comerciais é a diversidade de características físicas das mulheres apresentadas, com o objetivo de questionar os padrões de beleza usados na publicidade convencional, que são pautados principalmente pelos quesitos beleza, magreza e juventude. Apesar de promover um ideal de beleza mais abrangente, os comerciais ainda expõem a beleza e a aparência física como valores de grande importância na vida da mulher.

A mensagem transmitida sugere que a aparência deve ser cuidada, realçada e preservada através de cuidados estéticos. Há também a caracterização de alguns estereótipos do que seria uma representação de mulher independente, forte e empoderada. As imagens mostram mulheres em ambiente de trabalho, dirigindo automóveis, saindo juntas para festa. Os estereótipos não são necessariamente negativos, contudo também são utilizados como na publicidade convencional, para que o público absorva de maneira simples e imediata a mensagem.

Por meio da análise do corpus, foi percebido que o conceito de empoderamento feminino pode ser trabalhado de diferentes maneiras, dependendo dos interesses das marcas. Enquanto a Avon optou por frisar a união 
entre os diferentes tipos de mulheres, inclusive travestis, e a autoaceitação corporal, a Gillette Venus buscou numa autonomia feminina individual a sua forma de abordar o tema. Nesse último caso, uma crítica pertinente de Lana e Souza (2018) diz respeito à ligação do empoderamento feminino estritamente com a realização de desejos individuais, fato que esvaziaria o sentido do feminismo como um movimento coletivo.

Em linhas gerais uma das principais críticas, abordada por Klein (2004) na sua argumentação sobre o marketing de identidade, é a transformação de um movimento político e social numa "farra de compras". 0 consumo de produtos e serviços estaria tão intrinsicamente ligado ao empoderamento e ao feminismo, que se transformariam no principal requisito para a mulher se sentir independente e empoderada. Foi possível identificar que um grande desafio da sociedade seria verificar e pressionar as corporações para que esse tipo de discurso ativista não se resuma a ações e campanhas pontuais, mas sim se estenda a atuação no ambiente da empresa e na sociedade em geral.

\section{REFERÊNCIAS}

Agence France-Presse (2018, Julho 25). Ocupações feministas se espalham por centros de ensino no Chile. Carta Capital. Disponível em: <https://goo.gl/8Dshda>. Acesso em: 10 out. 2018.

Cardoso, R. \& Martino, N (2016, Janeiro 21). O novo feminismo. Isto é. Disponível em: <https://goo.gl/dni9um>. Acesso em: 10 out. 2018.

Carvalho, N.(2000) Publicidade. A linguagem da sedução (3ª ed.). São Paulo: Editora Ática.

Chernikoff, L (2014, Setembro 30). The Chanel Runway was also a feminist rally. ELLE. Disponível

em:

<https://www.elle.com/fashion/news/a1553

6/the-chanel-runway-was-also-a-feministprotest/>. Acesso em: 28 out. 2018.

Ciambriello, R. (2014 Outubro 13). How Ads That Empower Women Are Boosting Sales and Bettering the Industry. Adweek. Disponível em: $\quad<$ http://www.adweek.com/brandmarketing/how-ads-empower-women-areboosting-sales-and-bettering-industry160539/> Acesso em: 02 abr. 2018.

CDL.(2016, Fevereiro 26) SPC Brasil avalia perfil de consumo das mulheres brasileiras. CDL Petrópolis. Disponível em:
<https://goo.gl/86A1Az>. Acesso em: 10 jun. 2018.

Cruz, M.(2016). Representações do feminino na publicidade: Estereótipos, rupturas e deslizes. Revista Latinoamericana de Comunicación. 134, 181-200. São Paulo.

Duan, N. (2014, Outubro 3) A brief history of selling feminism. ELLE. Disponível em: <https://goo.gl/eWjWG7>. Acesso em: 03 mai. 2018

Fabris, T. Você sabe o que é femvertising?. (2015, Julho 23). B9. Disponível em: <http://www.b9.com.br/59594/advertising/ voce-sabe-o-que-e-femvertising/> Acesso em: 05 jul. 2017.

G1. (2017, Dezembro 13). Feminismo é eleita a palavra do ano pelo dicionário Americano. Disponível em: <https://goo.gl/a6LwaF>. Acesso em: 10 out. 2018.

Gil, A, C. (2008). Métodos e Técnicas de Pesquisa Social (6 ${ }^{\mathrm{a}}$ ed.). São Paulo: Atlas.

Gill, R. (2007). Advertising and Postfeminism. Gender and media. Cambridge. p. 73-112.

Heck, A. P \& Nunes, M. (2016) Publicidade e gênero: análise do fenômeno femvertising na criação de campanhas. Anais do XVII Congresso de Ciências da Comunicação na Região Sul. Curitiba.

Horochovski, R, R. (2006). Empoderamento: definições e aplicações. Anais do $30^{\circ}$ Encontro Anual da Anpocs, Caxambu - MG.

Klein, N. (2002). Sem logo: A tirania das marcas em um planeta vendido ( $3^{\mathrm{a}}$ ed.). Rio de Janeiro: Record.

Lana, L \& Souza, C.(2018). A consumidora empoderada: Publicidade, gênero e feminismo. Revista Intexto, UFRGS, E- ISSN 1807-8583. Porto Alegre.

Lysardo, D.(2007). A construção e a desconstrução de estereótipos pela publicidade brasileira. Stockholm Review of Latin American Studies, 2, 25-34.

Machado M., Burrowes, P., \& Rett, L. (2017). Para ler a publicidade expandida: em favor da literacia midiática para análise dos discursos das marcas. Anais do XXVI Encontro Anual da Compós, São Paulo - SP

Merigo, C.(2016, Março 15). SxSW 2016: Não basta anunciar para mulheres, é preciso contratar mulheres, .B9. Disponível em: <https://goo.gl/qb1UY7>. Acesso em: 04 abr. 2018

Mena, I. (2015, Março 6). Think Eva: A consultoria que quer ensinar a publicidade a respeitar a mulher. E lucrar com isso. Projeto Draft. Disponível em:< https://goo.gl/eE5yYh>. Acesso em: 25 jun. 2018. 
Nascimento, M, C. \& Dantas (2015). J. O Femvertising Evidência: Estudo de caso \#Likeagirl. Anais do Intercom - Sociedade Brasileira de Estudos Interdiciplinares de Comunicação. Rio de Janeiro - RJ

Rocha, E. (2001). A mulher, o corpo e o silêncio: a identidade feminina nos anúncios publicitários. Revista Alceu. 2(3), 15-39.

Santos, C. (2016) Beleza, magreza e juventude: a perfeição corporal feminina na publicidade e a corporeidade disruptiva da Dove. Revista Estudos em Comunicação, 35, 13-27.

Sheknows Media (2014 Outubro 1). SheKnows Media Hosts Femvertising panel at advertising week XI. SheKnows Media. Disponívem em: < https://bit.ly/2Zv13yT>. Acesso em: 26 abr. 2018.
Schroder, K \& Vestergaard, T. (2000). A linguagem da propaganda. São Paulo: Martins Fontes

Stocco, M. (2016, Fevereiro 16). E-commerce fatura R\$ 44,4 bilhões em 2016. Meio\&Mensagem. Disponível em:< https://goo.gl/4B4RSN>. Acesso em: 03 jan. 2018.

Think Eva. Manifesto. Think Eva. Disponível em:< http://www.thinkeva.com.br/manifesto/> Acesso em: 17 abri. 2018.

Think Olga. Sobre. Think Olga. Disponível em: <https://thinkolga.com/sobre/>. Acesso em: 17 abri. 2018.

Visconti, H. (2015, Outubro 22). Think Olga alerta para o assédio sexual de crianças com hashtag \#primeiroassédio. Época. Disponível em: <https://goo.gl/YPBZWt>. Acesso em: 10 out. 2018.

\title{
How to be a woman in advertising: Femvertising and "new" representations of femininity
}

\begin{abstract}
The present study aims to discuss whether and how the use of feminism in marketing, within the scope of femvertising, can transmit women's empowerment ideas and promote a representation of women in advertising that escapes stereotypes. To this end, three commercials that relied on the collaboration of feminist marketing consultancy Think Eva, are analysed: Avon's \#AreYouReady and This is for me, and Gillette's To be a woman makes all the difference. The methodology employed is the case study, using a model of critical reading of advertising for each individual commercial, and for a general approach of the data the stages of reduction, exhibition and conclusion/verification. The results indicate that body attributes, characteristic behaviour and the incentive to women's empowerment are the most reviewed issues in the commercials, and that they partially differ from the messages conveyed in conventional advertising.
\end{abstract}

Keywords: Advertising, Feminism, Feminist marketing, Femvertising 